ORIGINAL ARTICLE

\title{
Different responses of Korean pine (Pinus koraiensis) and Mongolia oak (Quercus mongolica) growth to recent climate warming in northeast China
}

\author{
Shanna Lyu ${ }^{\mathrm{a}}$, Xiaochun Wang, ${ }^{\mathrm{a}, *}$ Yuandong Zhang ${ }^{\mathrm{b}}$, Zongshan $\mathrm{Li}^{\mathrm{c}}$ \\ a Center for Ecological Research, College of Forestry, Northeast Forestry University, Harbin 150040, China \\ ${ }^{\mathrm{b}}$ Key Lab of Forest Ecology and Environment, State Forestry Administration, Institute of Forest Ecology, Environment and Protection, Chinese Academy of Forestry, Beijing \\ 100091, China \\ ' State Key Laboratory of Urban and Regional Ecology, Research Center for Eco-Environmental Sciences, Chinese Academy of Sciences, Beijing 100085, China
}

\section{A R T I C L E I N F O}

\section{Keywords:}

Radial growth

Tree rings

Relative humidity

The recent climate warming

The standard precipitation evapotranspiration

index

\begin{abstract}
A B S T R A C T
Different tree species growing in the same area may have different, or even contrasting growth responses to climate change. Korean pine (Pinus koraiensis) and Mongolia oak (Quercus mongolica) are two crucial tree species in temperate forest ecosystems. Six tree-ring chronologies for Korean pine and Mongolia oak were developed by using the zero-signal method to explore their growth response to the recent climate warming in northeast China. Results showed that Mongolia oak radial growth was mainly limited by precipitation in the growing season, while Korean pine growth depended on temperature condition, especially monthly minimum temperature. With the latitude decrease, the relationships between Korean pine growth and monthly precipitation changed from negative to positive correlation, while the positive correlation with monthly temperature gradually weakened. In the contrary, Mongolia oak growth at the three sampling sites was significantly and positively correlated with precipitation in the growing season, while it was negatively correlated with temperature and this relationship decreased with the latitude decrease. The radial growth of Korean pine at different sites showed a clearly discrepant responses to the recent warming since 1980. Korean pine growth in the north site increased with the temperature increase, decreased in the midwest site, and almost unchanged in the southeast site. Conversely, Mongolia oak growth was less affected by the recent climate warming. Our finding suggested that tree species trait and sites are both key factors that affect the response of tree growth to climate change. In addition, the suitable distribution area of Korean pine may be moved northward with the continued global warming in the future, but Mongolia oak may not shift in the same way.
\end{abstract}

\section{Introduction}

For the past one and half centuries (1880-2012), the Earth has been experiencing a changing process mainly characterized by climate warming, with the global average temperature increasing by approximately $0.85 \pm 0.15{ }^{\circ} \mathrm{C}$ (IPCC, 2013). Global warming is an indisputable fact, and will significantly impact plant growth (Shestakova et al., 2016), phenology (Wolkovich et al., 2012), vegetation distribution (Kelly and Goulden, 2008), and the structure and function of forest ecosystems (Grimm et al., 2013). The magnitude of warming in midhigh-latitude regions is larger than that in low-latitude regions, which means that forests in this area are likely more substantially affected by climate change (IPCC, 2013). Tree growth in high latitude of the northern hemisphere showed the increasing (Leonelli et al., 2009; Borgaonkar et al., 2011; Takahashi and Okuhara, 2012), decreasing (Briffa et al., 1998; Büntgen et al., 2006; Pisaric et al., 2007; Herguido et al., 2016) or invariable (Yu et al., 2005) trends in different areas to the recent climate warming.

Since the 1950s, the Northeast China has been one of the regions with the fastest speed and largest magnitude of warming in China, and experienced the most dramatic climate change since the 1980s (Ren et al., 2005; Zhao et al., 2009; He et al., 2013). The forest region in northeast China is the largest forest distribution area in high latitudes, China, and is also the central distribution area of the broad-leaved Korean pine (Pinus koraiensis) forest, which has been impacted substantially by climate warming (Ji, 2010; Wang et al., 2017). Therefore, the radial growth responses of Korean pine and Mongolia oak (Quercus mongolica), the two key tree species in the broad-leaved Korean pine forest, to the recent climate warming are crucial to predict the growth variations and dynamic of species composition in the broad-leaved Korean pine forest under the global climate change in the future.

A few of dendroclimatological studies have been conducted in the

\footnotetext{
* Corresponding author.

E-mail address: wangx@nefu.edu.cn (X. Wang).
} 
mixed coniferous-broadleaved forests in Xiaoxing'an Mountains, China (Ji, 2010). Climate warming could be causing the growth decline of Korean pine in its marginal distribution areas of Xiaoxing'an Mountains, and the response of Korean pine growth to climate change varied with different regions ( $\mathrm{Ji}, 2010)$. The recent climate warming decreased the Korean pine growth in the closed forests in Xiaoxing'an Mountains, but accelerated Korean pine growth in forest gaps, although the sampling sites were only limited in one site (Liangshui) (Zhu et al., 2015). The significant warming since 1980 may also be one of the factors causing the growth decline of Picea koraiensis in Xiaoxing'an Mountains (Yao et al., 2015). In addition, the growth of Phellodendron amurense and Fraxinus mandshurica in the northern Zhangguangcai Mountains, China could be conducive to global warming, while Juglans mandshurica growth exhibits a "divergence phenomenon" of slowing with the temperature increases (Su and Wang, 2017). The responses of a single coniferous or broad-leaved tree species at a single or different site to climate warming are different. However, there are few studies to identify whether the responses of the coniferous and broad-leaved trees in a gradient environment to recent warming are consistent or divergent.

Therefore, we conduct a study in Xiaoxing'an Mountains, China to understand the divergent effect of climate warming on the radial growth of the coniferous and broad-leaved trees at gradient sites. We use the tree-ring width of Korean pine and Mongolia oak collected from three sites (Hebei, Liangzihe, and Yongxing) in the central and eastern Xiaoxing'an Mountains to answer the following questions. Are there different growth-climate relationships for Korean pine and Mongolia oak growing at different sites? If the radial growth of the two trees species growing at the same site responds differently to the same climatic factors? With recent warming since the 1980s, does the sensitivity of Korean pine and Mongolia oak growth to temperature change?

\section{Materials and methods}

\subsection{Study area}

The study sites are located at a natural reserve of old-growth forest barely touched by human activity in the central and eastern region of Xiaoxing'an Mountains. We selected three sampling sites: the Hebei Forestry Bureau (HB), the Daliangzihe National Forest Park (LZH), and the Yongxing Forest Farm of the Dongfanghong Forestry Bureau (YX), respectively (Table 1 ). The study area is characterized by a temperate continental monsoon climate. The terrain features low mountains and hills. The broad-leaved Korean pine forest is vertically distributed from $300 \mathrm{~m}$ to $700 \mathrm{~m}$ above sea level (a.s.l.). The scattered Korean pine, however, can be found at $800 \mathrm{~m}$ a.s.l., and the lowest edge is at the elevation of $80-100 \mathrm{~m}$ a.s.l. The climate is a cold and dry winter and warm, moist, and rainy summer, with annual mean temperatures between -1 and $1{ }^{\circ} \mathrm{C}$. The average temperature in the hottest month (July) is $20-22{ }^{\circ} \mathrm{C}$, and temperatures in the coldest month (January) range from $-23^{\circ} \mathrm{C}$ to $-28^{\circ} \mathrm{C}$. The multi-year average precipitation is $550-700 \mathrm{~mm}$, mainly received in June-August which accounts for approximately $60-80 \%$ of the annual total precipitation. The annual frost- free period is 100-120 days. Soil is dominated by mountain dark-brown soil (Liu, 2012).

Two dominant tree species, Korean pine and Mongolia oak, in the natural broad-leaved Korean pine forest of northeast China were chosen. Korean pine is an intolerant conifer tree species with a shallow root system. It is highly sun-loving and has relatively high soil moisture requirements. Korean pine is not suitable to extreme dry or wet soils or a harsh climate, and is sensitive to air humidity. It grows best in a warm and rainy climate with relatively high humidity and in deep and fertile acidic brown forest soil with good drainage.

Mongolia oak is an intolerant broad-leaved tree species, which thrives in a cool climate. It can endure extreme cold and drought, and has no strict soil requirements. Mongolia oak can adapt to a broad range of soil types, although it mainly grows in relatively acidic or slightly acidic dark-brown and brown forest soils. Mongolia oak can endure barren but not wet soils. It is distributed from the top of low hills to ridges and various aspects with gentle inclines due to the developed root systems.

The vegetation of the broad-leaved Korean pine forest in this area is mainly dominated by Korean pine, the broad-leaved trees, such as Mongolia oak, F. mandshurica, P. amurense, Juglans mandshurica, Ulmus japonica, Tilia amurensis, Betula costata, and Acer mono, and other conifer trees such as Abies nephrolepis, Picea jezoensis etc. (Li, 1993).

\subsection{Field and laboratory work}

In June 2015, we collected tree-ring cores of Korean pine and Mongolia oak in Xiaoxing'an Mountains (Fig. 1). We used an increment borer with an inner diameter of $5.15 \mathrm{~mm}$ to take one or two cores at the opposite directions of the breast height $(1.3 \mathrm{~m})$ in each tree, and a total of 247 tree-ring cores were collected (Table 1).

All tree-ring samples were brought back to the laboratory, and were pasted, fixed, polished and visually cross-dated by busing the skeleton plot method under a binocular microscope based on the general procedures for processing tree-ring samples (Fritts, 1976; Stokes and Smiley, 1996). Then, we used a Velmex ring width measurement instrument (Velmex TA Tree Ring System, Velmex Inc.) to measure each ring width. The measurement accuracy was $0.001 \mathrm{~mm}$. Finally, the cross-dated results were checked and tested using the quality control program COFECHA (Holmes, 1983), then the wrong cross-dated results were corrected or the unsuccessful cross-dated tree-ring series was eliminated in the subsequent chronology development.

To alleviate the end effect and fitting deviation caused by the dramatic change of tree-ring series, we used the signal-free method to fit the growth trend curve (Melvin and Briffa, 2008). We used the linear or negative exponential functions to fit the growth trend and derive the growth trend of different tree-ring series. Then, we divided the original ring-width series by the fitting growth trend and derived the zero-signal series. Finally, we used the $67 \%$ length of each core to fit the zero-signal series and detrend again. After multiple iterations of the processes, we developed the tree-ring chronologies removing the non-climate signals, especially the end effects. The procedures of detrending and chronology development was accomplished using the RCSsigFree 4.5 software

Table 1

Tree-ring sampling information for different sites and tree species in northeast China.

\begin{tabular}{|c|c|c|c|c|c|c|}
\hline Sampled sites & Sample code & Tree species & Altitude (m) & Latitude (N) & Longitude (E) & Core/tree Numbers \\
\hline \multirow[t]{2}{*}{ HB } & HB-PK & P. koraiensis & 448 & $48^{\circ} 02^{\prime}$ & $130^{\circ} 18^{\prime}$ & $44 / 22$ \\
\hline & HB-QM & Q. mongolica & 258 & $48^{\circ} 11^{\prime}$ & $130^{\circ} 28^{\prime}$ & $42 / 21$ \\
\hline \multirow[t]{2}{*}{ LZH } & LZH-PK & P. koraiensis & 451 & $47^{\circ} 02^{\prime}$ & $129^{\circ} 41^{\prime}$ & $41 / 21$ \\
\hline & LZH-QM & Q. mongolica & 449 & $47^{\circ} 02^{\prime}$ & $129^{\circ} 40^{\prime}$ & $40 / 20$ \\
\hline \multirow[t]{2}{*}{ YX } & YX-PK & P. koraiensis & 161 & $46^{\circ} 40^{\prime}$ & $133^{\circ} 42^{\prime}$ & $40 / 20$ \\
\hline & YX-QM & Q. mongolica & 161 & $46^{\circ} 40^{\prime}$ & $133^{\circ} 42^{\prime}$ & $40 / 20$ \\
\hline
\end{tabular}

Notes: HB-Hebei, LZH-Liangzihe, YX-Yongxing. PK and QM represent the sampled tree species is Pinus koraiensis and Quercus mongolica, respectively. 

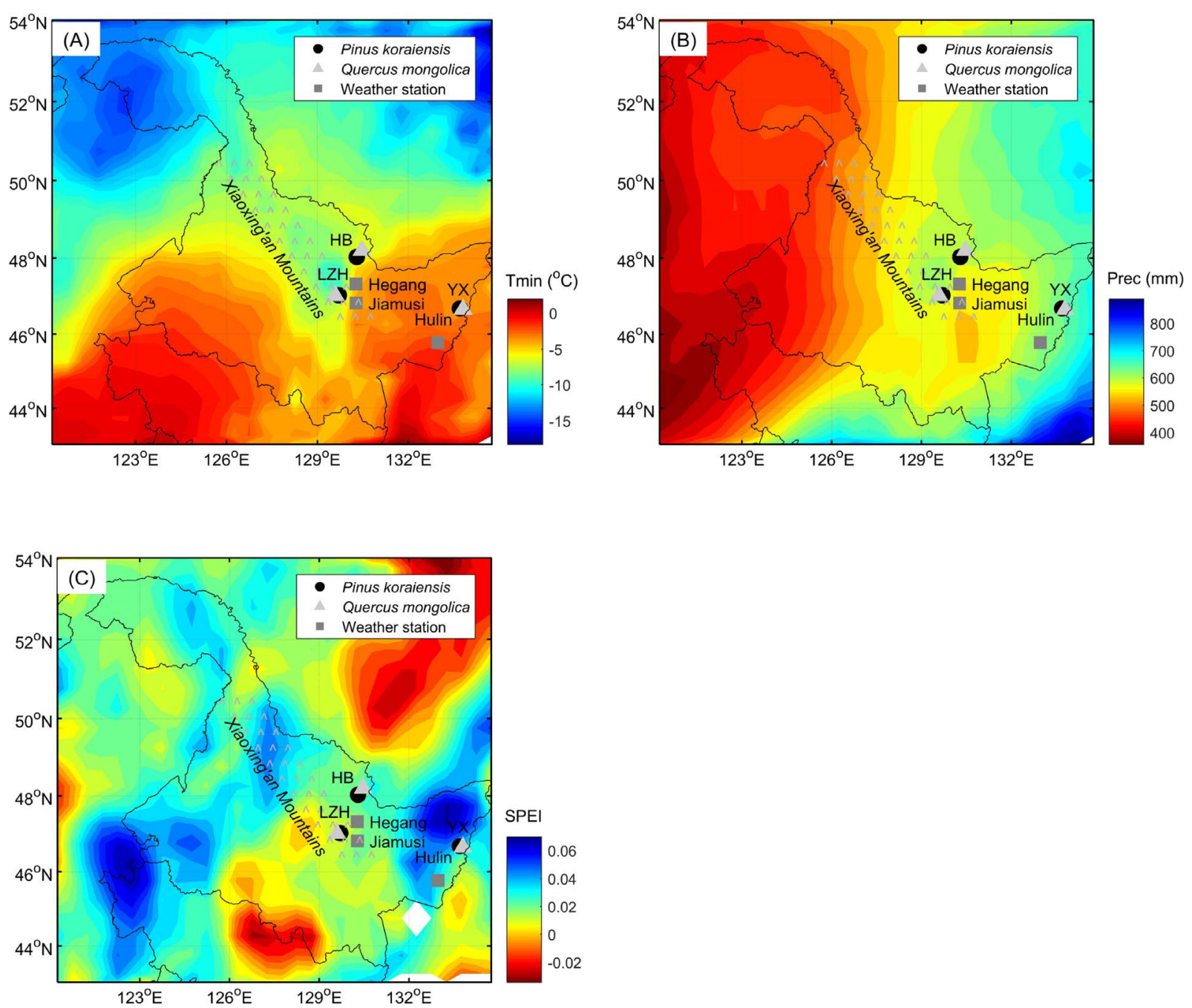

Fig. 1. Location map of sampled sites, weather stations and the spatial variation of the annual mean minimum temperature (Tmin), total precipitation (Prec) and the standard precipitation evapotranspiration index (SPEI) in northeast China.

\section{(Melvin and Briffa, 2008).}

\subsection{Statistical analysis}

The climatic data in this study were sourced from the China Meteorological Data Sharing Service Network (http://cdc.cma.gov.cn/ ). Three weather stations (Hegang, Jiamusi, and Hulin) close to each sampling site and in the same climatic region were chosen as the growth-climate analysis (Table 2). The climatic variables included the annual, seasonal, and monthly mean relative humidity (RH), precipitation, maximum temperature $\left(\mathrm{T}_{\max }\right)$, and minimum temperature $\left(\mathrm{T}_{\mathrm{min}}\right)$. In addition, we also calculated the monthly standard precipitation evapotranspiration index (SPEI) at the three sites (Vicenteserrano et al., 2010). The SPEI was constructed by combining the standard precipitation index (SPI) with potential evaporation. As tree growth is also influenced by climate in the previous year, the monthly climatic variable spanned from October in the previous year to September in the current year. Seasons were divided into winter (Dec-Feb), spring (Mar-May), summer (Jun-Aug), and autumn (Sep-Nov). The common period 1957-2008 was used as the compared correlation analysis of tree growth in three sites to the recent warming since 1980.

We analysed the relationship between the growth of Korean pine and Mongolia and different climatic factors. In addition, to examine the temporal stability of growth-climate relationship for Korean pine and Mongolia oak, the moving correlation analysis was conducted between the monthly $\mathrm{T}_{\min }$ and $\mathrm{RH}$ of the major months and tree-ring chronologies. All statistical analyses were performed by using IBM SPSS Statistics 24.0 software (International Business Machines Corp., 2016). The moving correlation window was 28 years, and one year was moved in each time.

Table 2

General information of meteorological station at each sampled site.

\begin{tabular}{|c|c|c|c|c|c|c|c|}
\hline Weather stations & Sampled sites & Period & Altitude (m) & Latitude (N) & Longitude (E) & $\mathrm{T}\left({ }^{\circ} \mathrm{C}\right)$ & $P(\mathrm{~mm})$ \\
\hline Hulin & YX & $1957-2014$ & 100 & $45^{\circ} 46^{\prime}$ & $132^{\circ} 58^{\prime}$ & 3.40 & 587 \\
\hline Jiamusi & LZH & $1951-2014$ & 812 & $46^{\circ} 49^{\prime}$ & $130^{\circ} 17^{\prime}$ & 3.40 & 544 \\
\hline Hegang & $\mathrm{HB}$ & 1956-2008 & 228 & $47^{\circ} 20^{\prime}$ & $130^{\circ} 16^{\prime}$ & 3.33 & 619 \\
\hline
\end{tabular}

Notes: $\mathrm{T}$ and $\mathrm{P}$ represents annual mean temperature and annul total precipitation. YX-Yongxing, LZH-Liangzihe, HB-Hebei. 
Table 3

Major statistical characteristics for the chronologies of Pinus koraiensis and Quercus mongolica in Xiaoxing'an Mountains, China.

\begin{tabular}{|c|c|c|c|c|c|c|}
\hline \multirow[t]{2}{*}{ Statistical Items } & \multicolumn{2}{|l|}{ LZH } & \multicolumn{2}{|l|}{$\mathrm{HB}$} & \multicolumn{2}{|l|}{ YX } \\
\hline & P. koraiensis & Q. mongolica & P. koraiensis & Q. mongolica & P. koraiensis & Q. mongolica \\
\hline Time span & $1685-2014$ & $1803-2014$ & $1691-2014$ & 1923-2014 & $1862-2014$ & 1759-2014 \\
\hline Mean sensitivity & 0.15 & 0.16 & 0.18 & 0.17 & 0.17 & 0.18 \\
\hline Standard deviation & 0.19 & 0.25 & 0.27 & 0.20 & 0.19 & 0.21 \\
\hline Mean correlations & 0.23 & 0.41 & 0.24 & 0.42 & 0.28 & 0.36 \\
\hline Autocorrelation order1 & 0.52 & 0.61 & 0.71 & 0.48 & 0.34 & 0.52 \\
\hline Signal-to-noise ratio & 5.41 & 13.59 & 6.47 & 14.62 & 6.27 & 10.74 \\
\hline Expressed population signal & 0.84 & 0.93 & 0.87 & 0.94 & 0.86 & 0.92 \\
\hline Variance in first eigenvector & $27.96 \%$ & $44.40 \%$ & $28.52 \%$ & $45.92 \%$ & $33.29 \%$ & $40.80 \%$ \\
\hline First year where EPS > 0.85 (No. of trees) & $1719(7)$ & $1815(6)$ & $1770(6)$ & $1932(8)$ & $1878(9)$ & $1846(7)$ \\
\hline
\end{tabular}

Notes: HB-Hebei, LZH-Liangzihe, YX-Yongxing.

\section{Results}

\subsection{Standard chronology and its characteristics in different sites}

The mean correlation coefficient, first-order autocorrelation, signalto-noise ratio, expressed population signal, and variance in first eigenvalue for the chronology of Mongolia oak were higher than those of Korean pine, which indicates that the chronology quality of Mongolia oak is better than that of Korean pine (Table 3). The statistical parameters of these chronologies in three sites also indicated that they were all suitable for dendroclimatological analysis.

The growth trend of Korean pine in the three sites before 1980 were similar (Fig. 2), but they were divergent after 1980. The Korean pine growth significantly increased in Hebei, decreased in Liangzihe, and almost kept horizontal in Yongxing with temperature increase.

The chronologies of Korean pine at three sites significantly correlated with each other $(p<0.05)$, while the chronologies of Mongolia oak were slightly different, that was, the chronology of Mongolia oak in Yongxing and Hebei did not significantly correlate (Table 4). The chronologies of Korean pine and Mongolia oak at Yongxing and Liangzihe significantly correlated $(p<0.05)$, while the correlation between the chronologies of Korean pine and Mongolia oak in Hebei

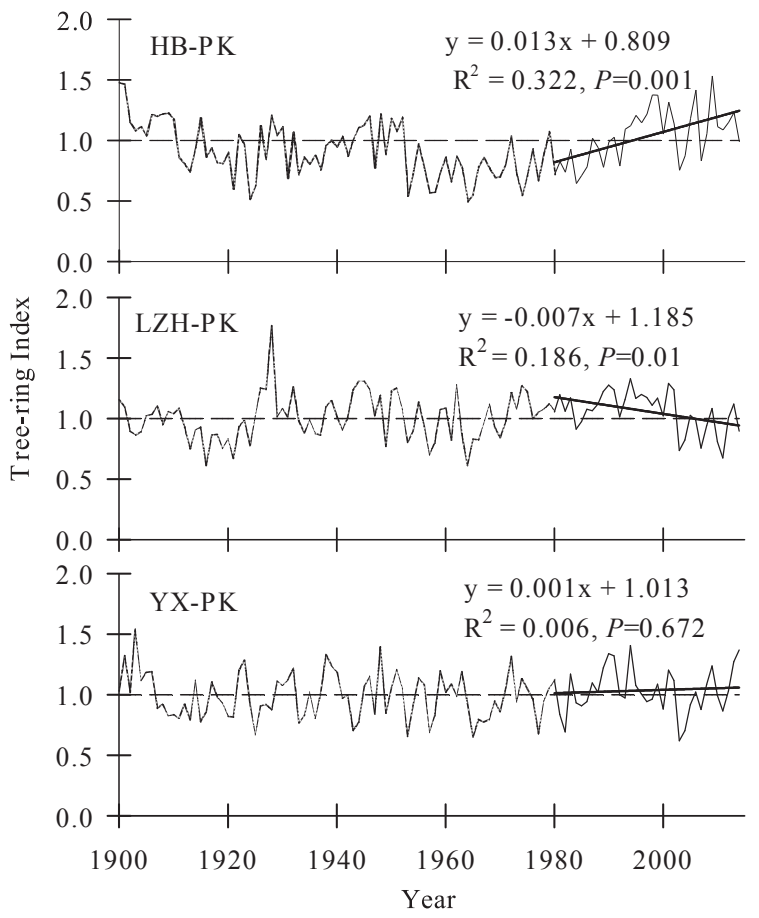

Table 4

Correlation coefficients for the chronologies of Pinus koraiensis and Quercus mongolica (common period 1923-2014).

\begin{tabular}{llllll}
\hline & HB-PK & LZH-PK & YX-PK & HB-QM & LZH-QM \\
\hline LZH-PK & $\mathbf{0 . 5 0 * *}$ & & & & \\
YX-PK & $\mathbf{0 . 4 3 * *}$ & $\mathbf{0 . 4 0 * *}$ & & & \\
HB-QM & -0.06 & -0.05 & 0.10 & & \\
LZH-QM & 0.14 & $\mathbf{0 . 2 3 *}$ & 0.12 & $\mathbf{0 . 4 1}$ & \\
YX-QM & $\mathbf{0 . 2 1 *}$ & 0.13 & $\mathbf{0 . 2 4}$ & 0.17 & $\mathbf{0 . 4 4 ^ { * * }}$ \\
\hline
\end{tabular}

Notes: HB-Hebei, LZH-Liangzihe, YX-Yongxing. PK and QM represent the sampled tree species is Pinus koraiensis and Quercus mongolica, respectively. The "*” and "***" represent the significance at the 0.05 and 0.01 level (two-tailed), respectively.

was not significant (Table 4).

\subsection{Variations of temperature and precipitation in the past 50 years}

The variation of the annual mean $\mathrm{T}_{\min }$ in the three sites during the period 1957-2008 was similar, while the variation of the SPEI was different. The $\mathrm{T}_{\min }$ and SPEI in three sites in the past 50 years can be divided into a stable period and warming period taking 1980 as the cut-

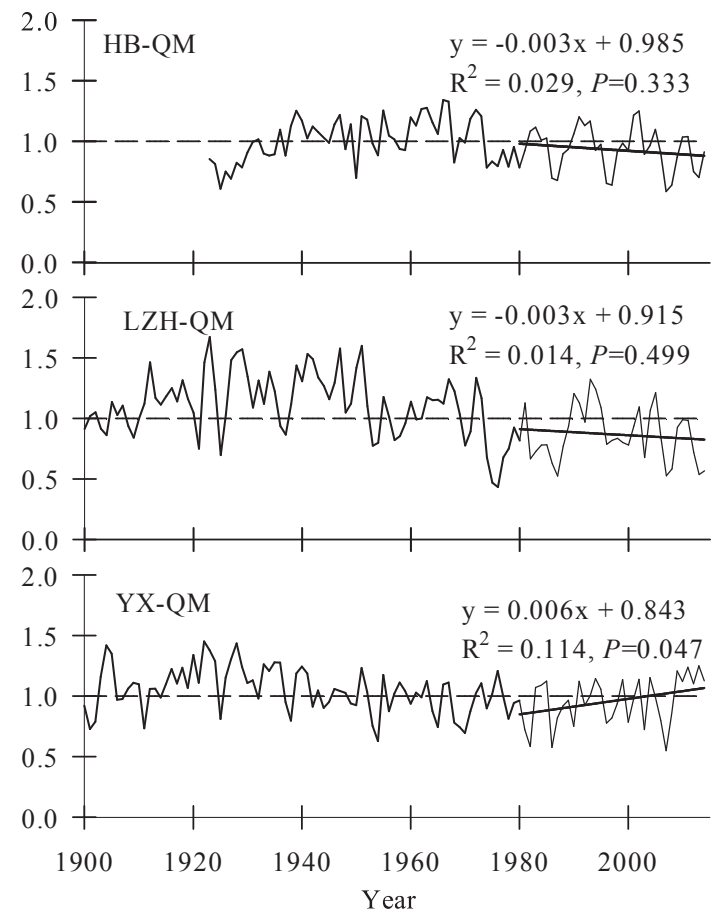

Fig. 2. Variations of the chronologies of Pinus koraiensis and Quercus mongolica in Xiaoxing'an Mountains. 


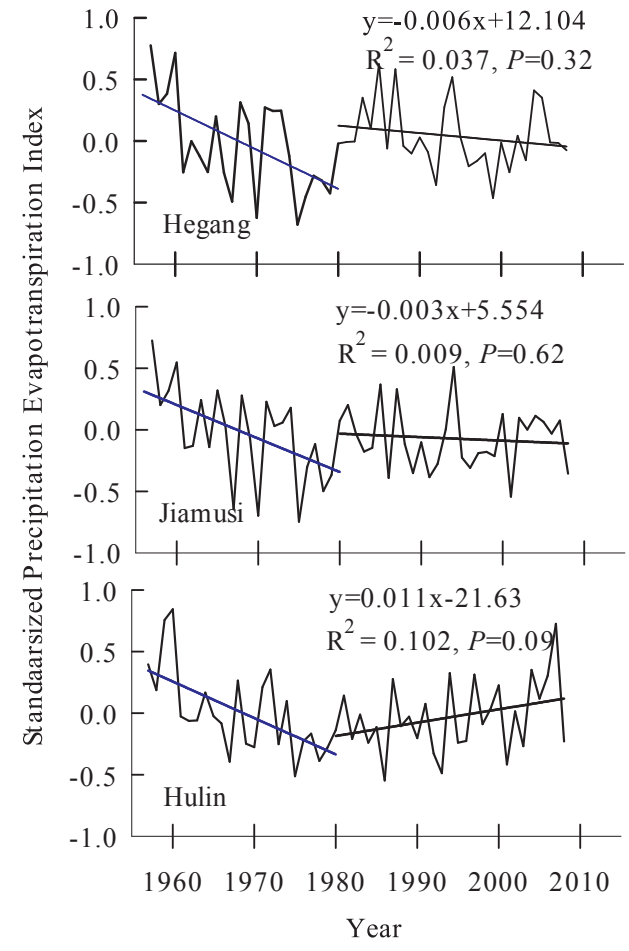

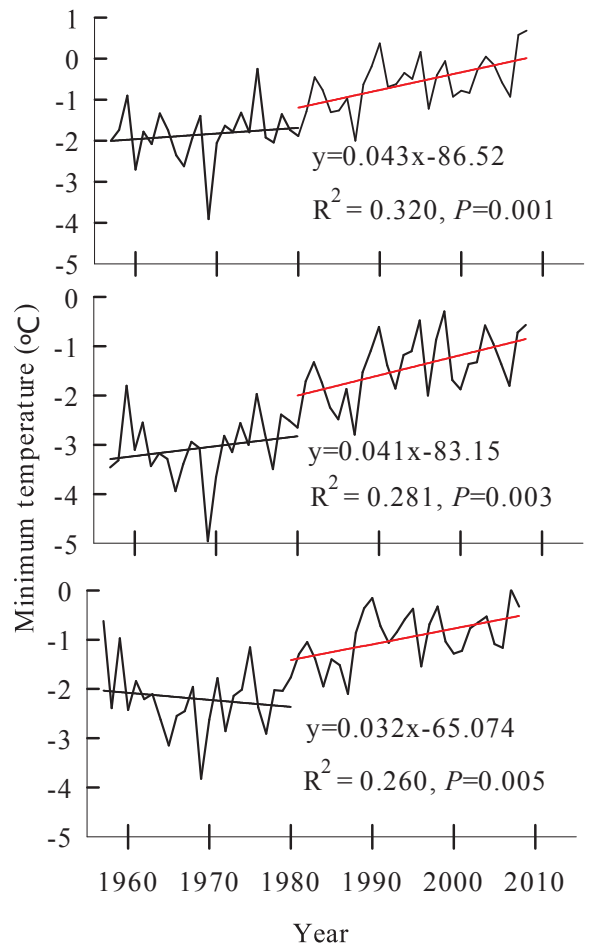

Fig. 3. Variation of annual mean minimum temperature and SPEI in Xiaoxing'an Mountain. off point. The temperature increased significantly since 1980 , but the warming magnitude at three sites was slightly different $\left(0.43^{\circ} \mathrm{C} \cdot 10 \mathrm{a}^{-1}\right.$ in Hegang; $0.41{ }^{\circ} \mathrm{C} \cdot 10 \mathrm{a}^{-1}$ in Jiamusi; $0.32{ }^{\circ} \mathrm{C} \cdot 10 \mathrm{a}^{-1}$ in Hulin). It experienced a significant drying trend at all three sites during the period 1957-1979. However, the SPEI varied at three sites since 1980: it was drier in Hegang, wetter in Hulin, and did not change much in Jiamusi (Fig. 3).

\subsection{Climate-growth relationship for Korean pine and Mongolia oak at different sites}

The correlation coefficients between Korean pine growth and the relative humidity during the growing season $\left(\mathrm{RH}_{\mathrm{GS}}\right.$, June-September) and SPEI at Hebei, Liangzihe, and Yongxing changes from negative to relatively weak and then to positive, while the correlation with temperature gradually weakens (left column of Fig. 4 and Table 5). The negative effects of temperature during the growing season on Mongolia oak growth at Hebei, Liangzihe, and Yongxing gradually decreased, while the positive effects of $\mathrm{RH}_{\mathrm{GS}}$ and the SPEI gradually increased and reached a significant level $(P<0.01)$ (right column of Fig. 4 and Table 5).

\subsection{Temporal variations of climate-growth relationship for Korean pine and Mongolia oak}

The moving correlation coefficients between Korean pine growth and the minimum temperature during the growing season $\left(\mathrm{T}_{\text {minGs }}\right)$ in Hebei changes from negative to positive during the period 1957-2008 (Fig. 5). The relationship between Korean pine growth and the $\mathrm{T}_{\text {minGs }}$ in Yongxing and Liangzihe varied from positive to negative since 1980, and the decreasing trend in Liangzihe is more obvious. The increasing trend in the moving correlation coefficients between Korean pine growth and $\mathrm{RH}_{\mathrm{GS}}$ was similar in the three sites, but it passed the significant level $(P<0.05)$ in Yongxing (Fig. 5).

The moving correlation coefficients between Mongolia oak growth and the $\mathrm{T}_{\text {minGs }}$ first increased and then decreased in the three sites, but it only reached the significant level in Yongxing (Fig. 5). However, the moving correlation coefficients between Mongolia oak growth and $\mathrm{RH}$ in the three sites showed divergent variation trend: it was higher than significant level before 1980s and sharply decreased since then in Liangzihe. On the contrary, it was lower than significant level $(P<0.05)$ before 1980 s and suddenly increased then and passed the significant level $(P<0.05)$ in Yongxing. The variation trend in Hebei was similar with it in Liangzihe, but it was always not significant (Fig. 5).

\subsection{Response of Korean pine and Mongolia oak growth in different sites to the recent climate warming}

The climate-growth relationships of Korean pine and Mongolia oak in the three sites obviously varied since the recent climate warming (Figs. 6-8). Before and after 1980, the correlation coefficient between the $\mathrm{T}_{\text {mings }}$ and Korean pine growth in Hebei changed from negative to positive value (Fig. 6); In Liangzihe, this relationship changed from positive to significantly negative correlation (Fig. 7); In Yongxing, it did not change significantly (Fig. 8). The positive relationship between Korean pine growth and $\mathrm{RH}_{\mathrm{GS}}$ increased significantly in Liangzihe (Fig. 7) and in Yongxing (Fig. 8) since 1980s. However, the negative relationship between Korean pine growth and RH in fall increased in Hebei (Fig. 6), while the positive relationship in Yongxing exhibited a significant downward trend since the recent climate warming (Fig. 8).

Before and after 1980, the negative relationship between Mongolia oak growth and the $\mathrm{T}_{\text {minGs }}$ increased in Hebei (Fig. 6), and the negative relationship between Mongolia oak growth and the fall $\mathrm{T}_{\min }$ became positive in Liangzihe (Fig. 7). No significant changes occurred in Yongxing (Fig. 8). The positive relationship between Mongolia oak growth and RH in winter increased in Hebei (Fig. 6), while the negative relationship with RH in spring became significantly positive. The positive relationship between Mongolia oak growth and $\mathrm{RH}_{\mathrm{GS}}$ increased in Liangzihe and Yongxing (Figs. 7 and 8).

\section{Discussion}

\subsection{Comparison of climate-growth relationship in different sites}

Growth-climate relationships of Korean pine and Mongolia oak 


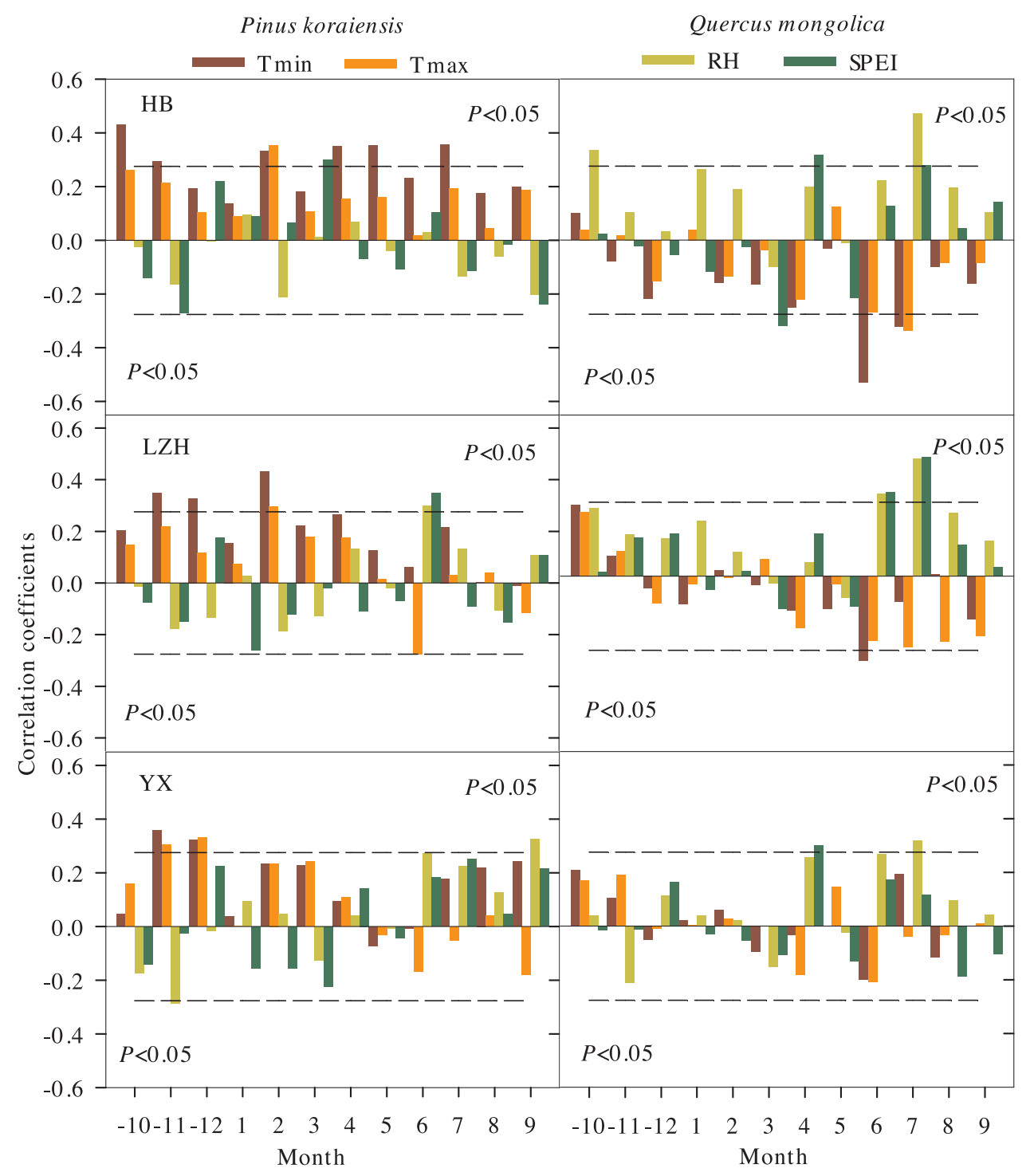

Fig. 4. Correlation analysis between climate (mean, maximum and minimum temperature, relative humidity and SPEI) and tree-ring standard chronologies of Pinus koraiensis, Quercus mongolica in three sampled areas. The horizontal dashed lines indicate statistically significant correlations at the $p<0.05$ level. varied in different sites due to the differences in geographic-spatial location of sampling sites and species traits. Hebei and Liangzihe are located in the central Xiaoxing'an Mountains which is high in elevation and warm and dry (Li, 2016). Climate and site conditions in Hebei are different from Liangzihe, which may lead to that Korean pine growths in Hebei and Liangzihe are more sensitive to temperatures in summer and in winter. A warm winter can reduce frost damage in plant issues and ensure normal metabolic activity in the next spring (Pederson et al., 2004). Although tree cambium activity ceases in winter, it still has physiological activities to keep trees alive, which is beneficial for tree growth in the coming year (Fritts, 1976; Gutiérrez, 1991; Gou et al., 2007). In addition, the rising temperature can accelerate the melting of snow in forests, lead to early cambium activity, and thus elongate the growing season, formatting a wide ring (Dang et al., 2007; Lo et al.,

Table 5

Correlation coefficients between the chronologies of Pinus koraiensis and Quercus mongolica and seasonal meteorological data.

\begin{tabular}{|c|c|c|c|c|c|c|c|}
\hline $\begin{array}{l}\text { Sites } \\
\text { Tree species }\end{array}$ & & $\begin{array}{l}\mathrm{HB} \\
\text { Korean pine }\end{array}$ & $\begin{array}{l}\text { LZH } \\
\text { Korean pine }\end{array}$ & $\begin{array}{l}\mathrm{YX} \\
\text { Korean pine }\end{array}$ & $\begin{array}{l}\text { HB } \\
\text { Mongolia oak }\end{array}$ & $\begin{array}{l}\text { LZH } \\
\text { Mongolia oak }\end{array}$ & $\begin{array}{l}\text { YX } \\
\text { Mongolia oak }\end{array}$ \\
\hline \multirow[t]{5}{*}{ Minimum temperature } & Annual & $0.42^{* *}$ & $0.30^{*}$ & 0.27 & $-0.28^{*}$ & -0.12 & -0.04 \\
\hline & Winter & $0.29 *$ & $0.36 * *$ & 0.26 & -0.16 & -0.02 & 0.17 \\
\hline & Spring & $0.34^{* *}$ & 0.25 & 0.15 & -0.20 & -0.10 & -0.07 \\
\hline & Summer & $0.35^{* *}$ & 0.13 & 0.18 & $-0.46^{* *}$ & -0.20 & -0.07 \\
\hline & Autumn & 0.24 & 0.06 & 0.27 & -0.14 & -0.02 & 0.07 \\
\hline \multirow[t]{5}{*}{ Relative humidity } & Annual & -0.09 & 0.03 & 0.26 & $0.37 * *$ & $0.32 *$ & 0.23 \\
\hline & Winter & -0.07 & -0.12 & 0.05 & 0.21 & 0.18 & 0.06 \\
\hline & Spring & -0.02 & -0.02 & -0.05 & 0.04 & -0.03 & 0.03 \\
\hline & Summer & -0.06 & 0.18 & $0.30^{*}$ & $0.40^{* *}$ & $0.44^{* * *}$ & $0.32^{*}$ \\
\hline & Autumn & -0.09 & 0.08 & $0.33^{*}$ & 0.20 & 0.25 & 0.12 \\
\hline
\end{tabular}

Notes: HB-Hebei, LZH-Liangzihe, YX-Yongxing. The “*” and “**” represent the significance at the 0.05 and 0.01 level (two-tailed), respectively. 

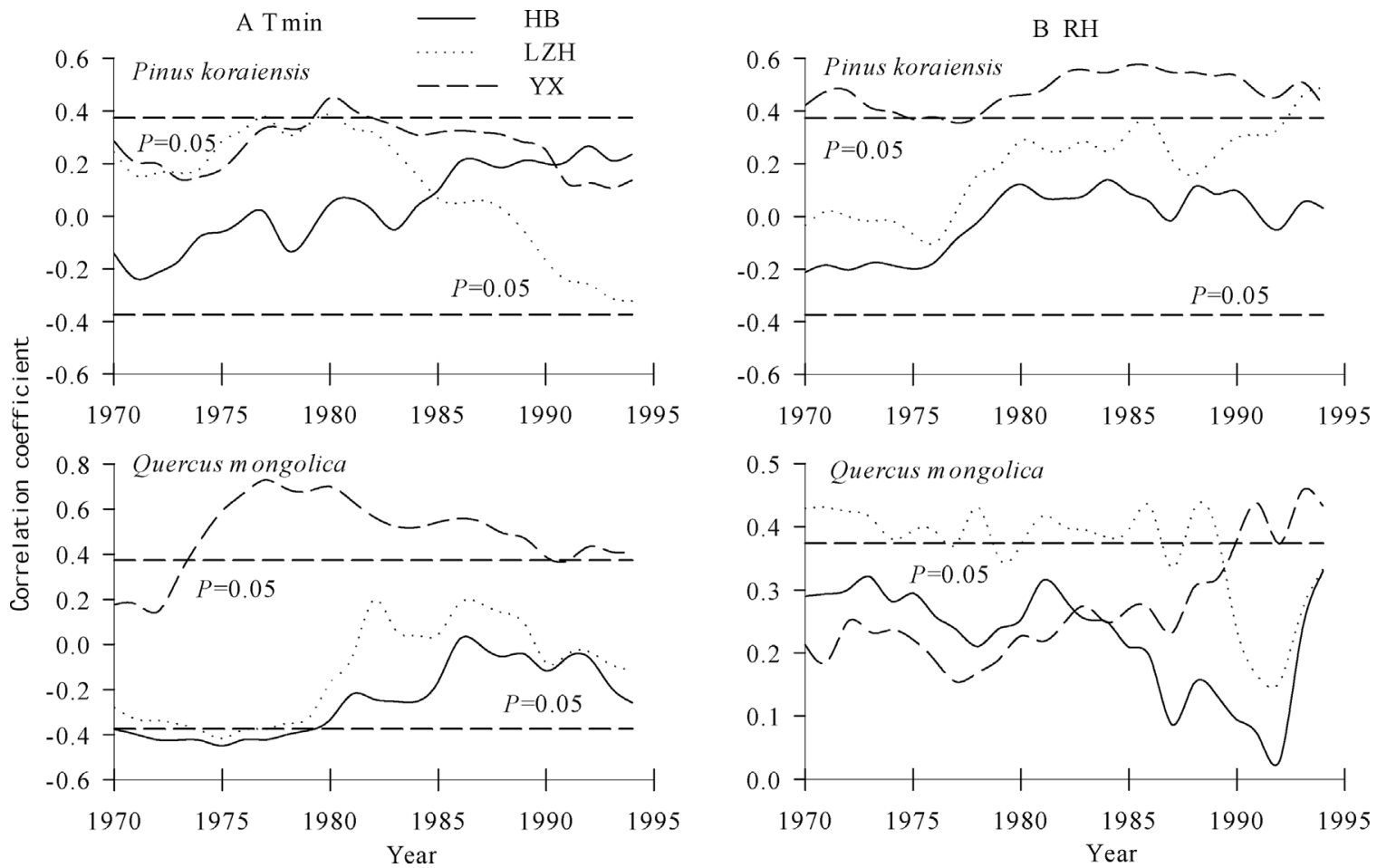

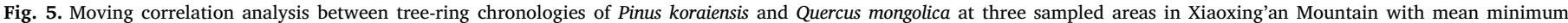
temperature $\left(\mathrm{T}_{\min }, \mathrm{A}\right)$ and relative humidity $(\mathrm{RH}, \mathrm{B})$ during growing season. The horizontal dashed lines indicate statistically significant correlations at the $p<0.05$ level.

2010). Yongxing is in the eastern Xiaoxing'an Mountains which is in low elevation, warm and humid. The Korean pine growth is mainly limited by autumn temperature and soil moisture in Yongxing. Although autumn is the latter part of the growing season, the photosynthesis is still in progress (Fritts, 1976). Better hydrothermal conditions can produce sufficient nutrients and photosynthate for tree growth in the current and coming year. However, the decreasing $\mathrm{T}_{\text {min }}$ may decrease respiratory consumption, which can accumulate photosynthetic products in tree stem and accelerates growth (Wang et al., 2011).
Adequate precipitation conditions in fall can increase soil moisture and provide the necessary water for tree to grow in the following year (Cleaveland et al., 2003). Although the three sampling sites are located in Xiaoxing'an Mountains, the soil moisture during the growing in each sampling site is different, which will lead to the different radial growth. High photosynthesis leads to more differentiation of wood cells if soil moisture is sufficient during the growing season, and then form wide rings (Fritts, 1992). In contrast, less precipitation accompanied by high temperatures during the growing season will cause soil water deficit, and thus restricts tree growth (Barber et al., 2000). That may be the

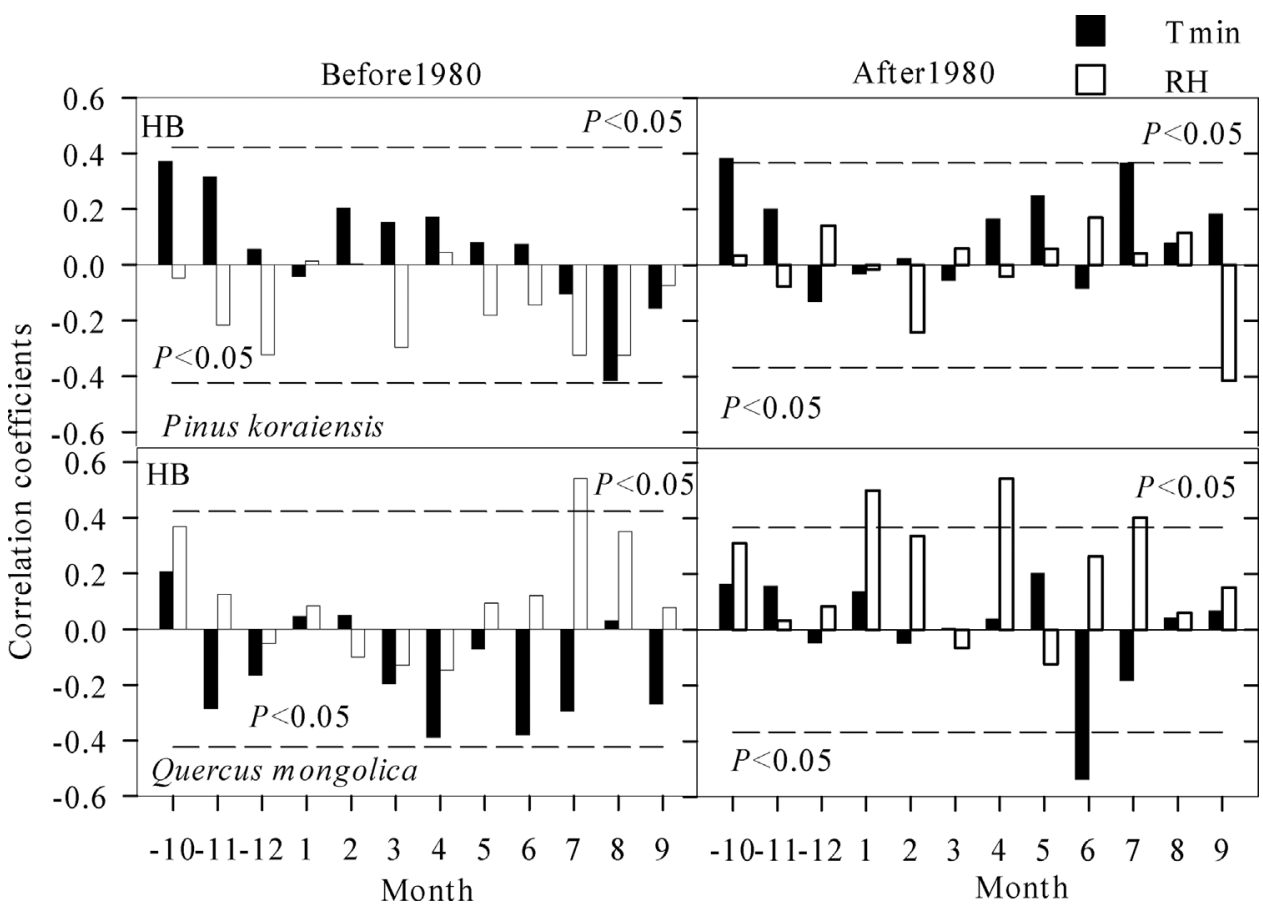

Fig. 6. Correlation between tree-ring chronologies of Pinus koraiensis and Quercus mongolica at Hebei (HB) area with monthly mean minimum temperature and relative humidity around rapid warming. The horizontal dashed lines indicate statistically significant correlations at the $p<0.05$ level. 


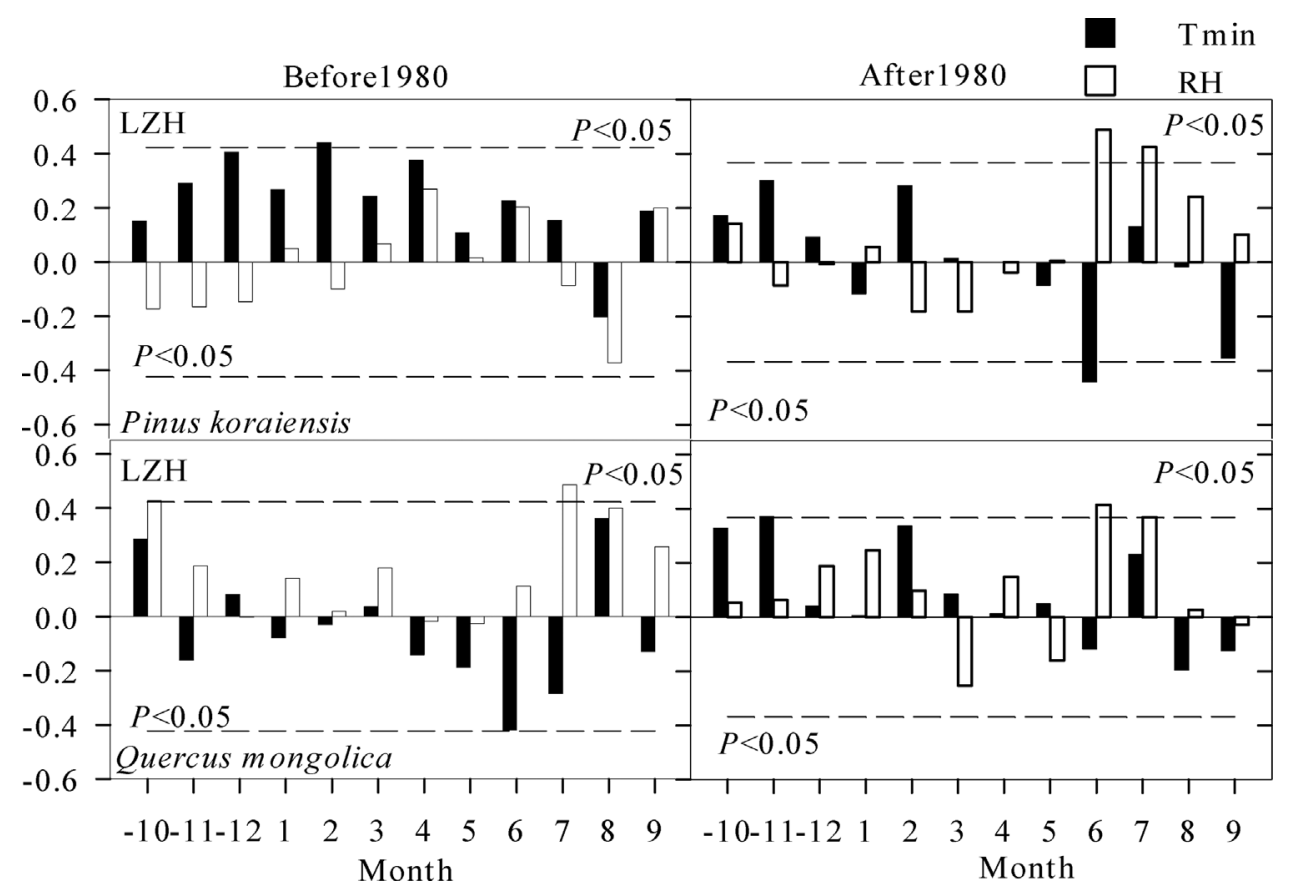

Fig. 7. Correlation between tree-ring chronologies of Pinus koraiensis and Quercus mongolica at Liangzihe (LZH) area with monthly mean minimum temperature and relative humidity around rapid warming. The horizontal dashed lines indicate statistically significant correlations at the $p<0.05$ level. reason that the growth-climate relationships of Korean pine at the three sampling sites change from negative to significantly positive correlation (Wimmer and Grabner, 1997). In addition, the different growth-climate relationship of Korean pine at the three sites may also result from the different site elevations, that is, the radial growth at lower elevations was limited by precipitation, while it was much more affected by minimum temperature at higher elevations (Yu et al., 2013).

The negative correlation between Mongolia oak growth and the $\mathrm{T}_{\text {minGs }}$ gradually weakened from north to south, which was consistent with the results of Siberian larch (Larix sibirica) in western Altai, China (Li et al., 2011). This may be due to an increase in precipitation from north to south, thereby reducing the negative effects of temperature on growth (Fig. 1). High minimum temperatures were associated with much lower growth. Higher nighttime temperatures will lead to an increase in respiration and thus increase nighttime carbon loss and reduce growth (Sullivan et al., 2015). Also, high temperatures can aggravate evaporation of soil moisture and transpiration of plants, thus lead to soil drought stress and reduce growth (Williams et al., 2013).

\subsection{Different climate-growth relationship of the two trees species}

The radial growth of Korean pine in Xiaoxing'an Mountains is mainly limited by the $\mathrm{T}_{\text {mings }}$. Korean pine belongs to a heliophilous tree species with a shallow root system (Thomas and Farjon, 2013). It is highly sun-loving and requires a relatively high moisture in soil, which should not be overly dry or wet (Wu and Raven, 1999). It often grows on wet slopes with good drainage. The temperature tolerance range of Korean pine is relatively large, but its soil moisture requirements are stringent, and its response to soil drainage and ventilation conditions is sensitive (Weber et al., 2007; Eilmann et al., 2006). The negative influence of June temperatures on the growth of Korean pine follows previous studies that indicate the water availability at the beginning of

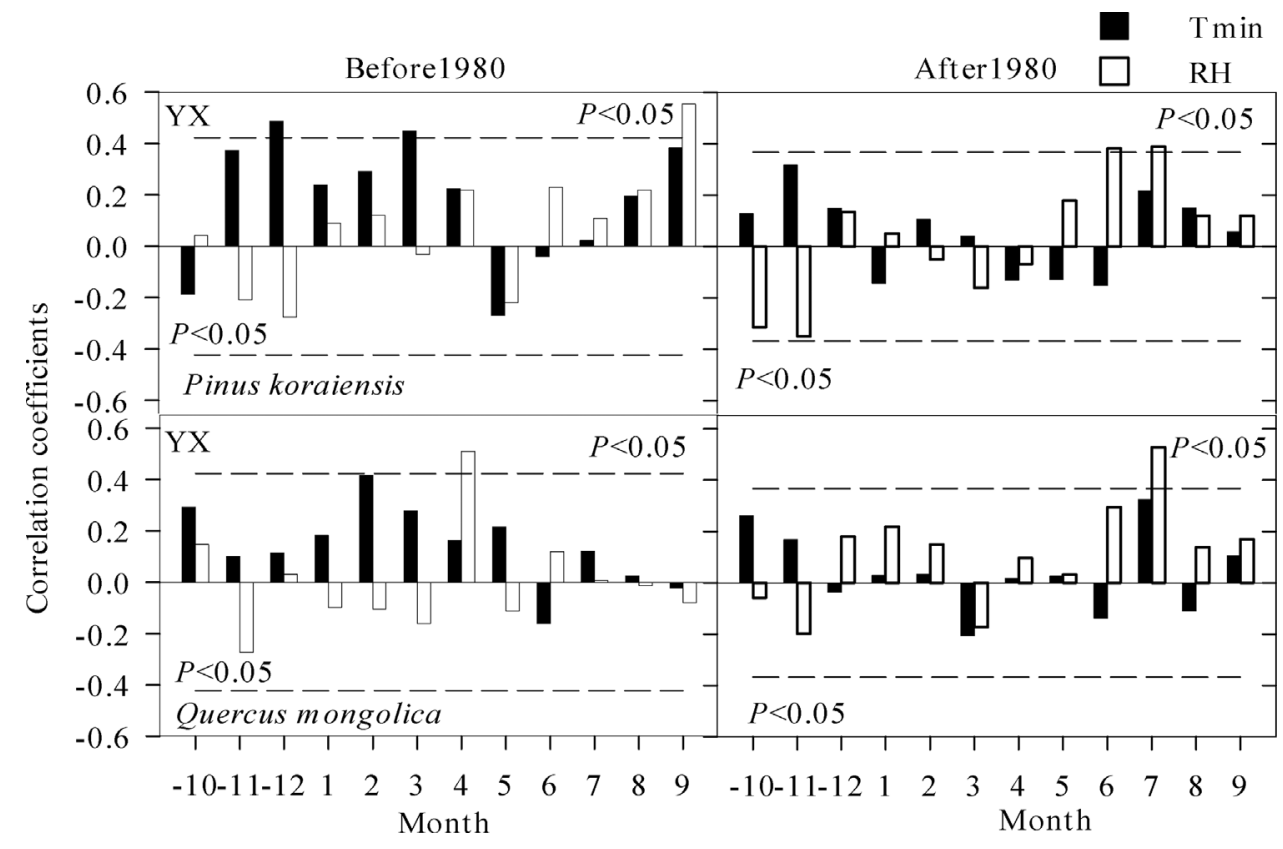

Fig. 8. Correlation between tree-ring chronologies of Pinus koraiensis and Quercus mongolica at Yongxing (YX) area with monthly mean minimum temperature and relative humidity around rapid warming. The horizontal dashed lines indicate statistically significant correlations at the $p<0.05$ level. 
Table 6

Changes of the Gini coefficient of Pinus koraiensis and Quercus mongolica raw chronologies before and after rapid warming (1980) of three sampled areas in Xiaoxing'an Mountain.

\begin{tabular}{lll}
\hline Chronology & Before 1980 & After 1980 \\
\hline HB-PK & 0.54 & 0.84 \\
HB-QM & 0.57 & 0.50 \\
LZH-PK & 0.40 & 0.56 \\
LZH-QM & 0.39 & 0.39 \\
YX-PK & 0.54 & 0.68 \\
YX-QM & 0.70 & 0.36
\end{tabular}

Notes: HB-Hebei, LZH-Liangzihe, YX-Yongxing. PK and QM represent the sampled tree species is Pinus koraiensis and Quercus mongolica, respectively.

growing season is critical for its growth (Wang et al., 2017). Therefore, elevated growing season temperatures, coupled with decreased precipitation, can cause drought stress due to high evapotranspiration rates, which may reduce the levels of stored carbohydrates, resulting in lower ring-width growth (Fritts, 1976; Tardif and Stevenson, 2001).

The radial growth of Mongolia oak in Xiaoxing'an Mountains is mainly limited by the combined temperature and the moisture conditions during the growing season. Mongolia oak is wet intolerant and more sensitive to soil moisture than temperature (Zhou et al., 2002). Proper soil moisture during the growing season can promote the radial growth of Mongolia oak, while a negative correlation between Mongolia oak in Hebei and Liangzihe and the $\mathrm{T}_{\min G s}$ also indicates that a rise in the $T_{\text {min }}$ enhances respiration of plants at night. The products of photosynthesis are certain, and respiration consumes most those products, causing a reduction in nutrients available for tree growth, thus slowing or limiting tree growth (Liang et al., 2001; Williams et al., 2013). The different growth-climate relationships of the two tree species at the same site may mainly result from the different tree traits, such as physiological properties and structures (He et al., 2005), and there are clear differences in genetic specificities among species, which is consistent with previous studies (Friedrichs et al., 2009; Jiang et al., 2014).

\subsection{Different growth response of the two tree species to the recent climate warming}

Since the 1950s, the annual mean temperature in northeast China exhibited a significant warming trend with an increasing rate of $0.22{ }^{\circ} \mathrm{C} \cdot 10 \mathrm{a}^{-1}$ (Ding et al., 2006). The warming trend of the annual mean $\mathrm{T}_{\text {min }}$, with an increasing rate of approximately $0.29^{\circ} \mathrm{C} \cdot 10 \mathrm{a}^{-1}$, is larger than that of the $\mathrm{T}_{\max }$. The mean $\mathrm{T}_{\min }$ exhibits an increasing trend in all seasons and more obvious in winter, particularly in northeast China (Tang et al., 2005; Ding et al., 2006). Climate warming has influenced the radial growth of coniferous and broad-leaved tree species in northeast China (Ji, 2010). The variation of the Gini coefficient for Korean pine and Mongolia oak growth (Table 6) indicates that significant growth changes of Korean pine since the recent warming occurred in the three sites, especially in Hebei. The Mongolia oak growth varied significantly before and after 1980 in Yongxing, while it did not substantially change in the other two sites (Table 6).

The $\mathrm{T}_{\text {minGs }}$ negatively affects Korean pine growth and gradually increases since the recent climate warming, which may result from the synchronous constraint effect of hydrothermal coupling on the growth of Korean pine in this region (Wang et al., 2017). As temperature increases, the evapotranspiration of water content in soil and tree transpiration both accelerate (Büntgen et al., 2006), and the moisture conditions satisfying growth requirements in normal year may become the limited factor when it exceeds a certain threshold. Thus, the decrease of the soil water availability will exaggerate the drought stress phenomenon (Andreu et al., 2007) and then reduce Korean pine growth. Therefore, Korean pine exhibited a clear growth decline in this area since the temperature rising, which is widely confirmed in the mid- high-latitude regions (Cook et al., 2004; Esper and Frank, 2009; Zhang and Wilmking, 2010; Matisons et al., 2012).

It is worth noting that the growth decline phenomenon of Korean pine gradually weakened with the northward latitude increasing, and the temperature rising in fall intensifies the moisture constraint on the radial growth of Korean pine. Although various tissues and organs in trees have ceased growing at the end of the growing season, some photosynthesis still occurs when moisture conditions are satisfied (Salzer et al., 2009). It will be conducive to accumulating more photosynthetic products and provides sufficient nutrients for cambium formation activity in the next spring (Wimmer and Grabner, 1997). In addition, the sufficient precipitation in fall can improve soil moisture, and then ensure tree growth in the coming year (Wu, 2003; Wu and Deng, 1996). Although the $\mathrm{T}_{\min }$ in summer increased since the recent climate warming, it may not exceed the temperature threshold of Mongolia growth. Especially, the drought caused by temperature rising did not exceed the threshold of Mongolia oak growth, so it did not change significantly with the recent climate warming since 1980, which is also confirmed by Zhou et al. (2002).

\section{Conclusions}

We used the dendrochronological method to investigate the influence of recent climate warming on radial growth of Korean pine and Mongolia oak in the central and eastern area of Xiaoxing'an Mountains, China. The influence of the recent warming on the radial growth of Korean pine varied in different sites, while it did not significantly affect or slightly increased Mongolia oak growth. In addition, Korean pine growth decline caused by the recent warming gradually decreased with the latitude increase, and the suitable distribution of Korean pine forest may shift north with climate warming. In southern areas, Mongolia oak may replace Korean pine in the mixed broadleaved-pine forest. The divergent climate-growth relationship for Korean pine and Mongolia oak in the same area indicate that the species-specific genetic characteristics are crucial factors in tree growth response to climate change. The site is another key factor that determined how tree growth response to climate change. Therefore, the divergent response mechanisms of pine and oak species will occur in different regions.

\section{Acknowledgments}

This research was supported by the National Natural Science Foundation of China (41471168), the Key Project of the China National Key Research and Development Plan (2016YFA0600800), the Fundamental Research Funds for the Central Universities (2572017EA02), and the Program for Changjiang Scholars and Innovative Research Team in University (IRT-15R09).

\section{References}

Andreu, L., Gutierrez, E., Macias, M., Ribas, M., Bosch, O., Camarero, J., 2007. Climate increases regional tree- growth variability in Iberian pine forests. Glob. Change Biol, 13, 804-815.

Büntgen, U., Frank, D.C., Schmidhalter, M., Neuwirth, B., Seifert, M., Esper, J., 2006. Growth climate response shift in a long subalpine spruce chronology. Trees 20, 99-110.

Barber, V.A., Juday, G.P., Finney, B.P., 2000. Reduced growth of Alaskan white spruce in the twentieth century from temperature-induced drought stress. Nature 405 , 668-673.

Borgaonkar, H.P., Sikder, A.B., Ram, S., 2011. High altitude forest sensitivity to recent warming: a tree-ring analysis of conifers from Western Himalaya, India. Quat. Int. 236, 158-166.

Briffa, K.R., Schweingruber, F.H., Jones, P.D., Osborn, T.J., Shiyatov, S.G., Vaganov, E.A., 1998. Reduced sensitivity of recent tree-growth to temperature at high northern latitudes. Nature 391, 678-682.

Cleaveland, M.K., Stahle, D.W., Therrell, M.D., Villanueva-Diaz, J., Burns, B.T., 2003. Tree-ring reconstructed winter precipitation and tropical teleconnections in Durango, Mexico. Clim. Change 59, 369-388.

Cook, E.R., Esper, J., D’Arrigo, R.D., 2004. Extra-tropical Northern Hemisphere land temperature variability over the past 1000 years. Quat. Sci. Rev. 23, 2063-2074. 
Dang, H., Jiang, M., Zhang, Q., Zhang, Y., 2007. Growth responses of subalpine fir (Abies fargesii) to climate variability in the Qinling Mountain, China. For. Ecol. Manag. 240, $143-150$.

Ding, Y., Ren, G., Shi, G., Gong, P., Zhang, D., Zhai, P., Zhang, D., Zhao, Z., Wang, S., Wang, H., Luo, Y., Chen, D., Gao, X., Dai, X., 2006. National Assessment Report of Climate Change (I): climate change in China and its future trend. Adv. Clim. Change Res. 2, 3-8.

Eilmann, B., Weber, P., Rigling, A., Eckstein, D., 2006. The influence of drought on the wood structure of Pinus sylvestris L. and Quercus pubescens Willd in Valais, Switzerland. Dendrochronologia 23, 121-132.

Esper, J., Frank, D., 2009. Divergence pitfalls in tree-ring research. Clim. Change 94 261-266.

Friedrichs, D.A., Neuwirth, B., Winiger, M., Löffler, J., 2009. Methodologically induced differences in oak site classifications in a homogeneous tree-ring network. Dendrochronologia 27, 21-30.

Fritts, H.C., 1976. The statistics of ring width and climate data. Tree Rings and Climate. Academic Press, London.

Fritts, H.C., 1992. Dendrochrological modeling of the effects of climatic change on treering width chronologies from the Chaco Canyon area, southwestern United States. Tree-Ring Bull. 52, 31-58.

Gou, X., Chen, F., Yang, M., Gordon, J., Fang, K., Tian, Q., Zhang, Y., 2007. The highest and minimum temperature asymmetric changes revealed by tree-ring records in the northeastern Tibetan Plateau. Sci. China Ser. C 37, 1480-1492 (in Chinese).

Grimm, N.B., Chapin, F.S., Bierwagen, B., Gonzalez, P., Groffman, P.M., Luo, Y.Q., Melton, F., Nadelhoffer, K., Pairis, A., Raymond, P.A., Schimel, J., Williamson, C.E., 2013. The impacts of climate change on ecosystem structure and function. Front. Ecol. Environ. 11, 474-482.

Gutiérrez, E., 1991. Climate tree-growth relationships for Pinus uncinata Ram. in the Spanish Pre-Pyrenees. Acta Oecol. 12, 213-225.

He, J., Zhang, Q., Bazzaz, F.A., 2005. Differential drought responses between saplings and adult trees in four co-occuring species of New England. Trees 19, 442-450.

He, W., Bu, R., Xiong, Z., Hu, Y., 2013. Characteristics of temperature and precipitation in Northeastern China from 1961 to 2005. Acta Ecol. Sin. 33, 519-531.

Herguido, E., Granda, E., Benavides, R., Garcia-Cervigon, A.I., Camarero, J.J., Valladares, F., 2016. Contrasting growth and mortality responses to climate warming of two pine species in a continental Mediterranean ecosystem. For. Ecol. Manag. 363, 149-158.

Holmes, R.L., 1983. Computer-assisted quality control in tree-ring dating and measurement. Tree-Ring Bull. 43, 69-78.

IPCC, 2013. The Physical Science Basis. Contribution of Working Group I to the Fifth Assessment Report of the Intergovernmental Panel on Climate Change Cambridge. Cambridge University Press, Cambridge, UK and New York, USA.

Ji, Y., 2010. Climate-Growth Relationships of Korean Pine in Heilongjiang and Their Potential for Global Warming. Northeast Forestry University, Harbin.

Jiang, Y., Zhang, W., Wang, M., Kang, M., Dong, M., 2014. Radial growth of two dominant montane conifer tree species in response to climate change in North-central China. PLoS One 9, e112537.

Kelly, A.E., Goulden, M.L., 2008. Rapid shifts in plant distribution with recent climate change. Proc. Natl. Acad. Sci. 105, 11823-11826.

Leonelli, G., Pelfini, M., Battipaglia, G., Cherubini, P., 2009. Site-aspect influence on climate sensitivity over time of a high-altitude Pinus cembra tree-ring network. Clim. Change 96, 185-201.

Li, M., Yuan, Y., Wei, W., Zhang, T., Qin, L., 2011. Characteristics of tree-ring width chronologies in western Altay and their response to climate change. Desert Oasis Meteorol. 5, 16-21.

Li, J., 1993. Heilongjiang Forest. Northeast Forestry University Press, Harbin.

Li, K., 2016. Study on sustainable management of forestry resources-a case study in Hebei Forestry Bureau. For. Eng. 32, 12-15.

Liang, E., Shao, X., Hu, Y., Lin, J., 2001. Dendroclimatic evaluation of climate-growth relationships of Meyer spruce (Picea meyeri) on a sandy substrate in semi-arid Grassland, North China. Trees 15, 230-235.

Liu, L., 2012. Study on the Plant Biodiversity and Ecosystem Service Functions Evaluation of Forest Ecosystem in Xiaoxing'an Mountains. Northeast Forestry University, Harbin.

Lo, Y.H., Blanco, J.A., Seely, B., Welham, C., Kimmins, J.P., 2010. Relationships between climate and tree radial growth in interior British Columbia, Canada. For. Ecol. Manag. 259, 932-942.

Matisons, R., Elferts, D., Brūmelis, G., 2012. Changes in climatic signals of English oak tree-ring width and cross-section area of early wood vessels in Latvia during the period 1900-2009. For. Ecol. Manag. 279, 34-44.

Melvin, T.M., Briffa, K.R., 2008. A signal-free approach to dendroclimatic standardization. Dendrochronologia 26, 71-86.

Pederson, N., Cook, E.R., Jacoby, G.C., Peteet, D.M., Griffin, K.L., 2004. The influence of winter temperatures on the annual radial growth of six northern range margin tree species. Dendrochronologia 22, 7-29.

Pisaric, M.F.J., Carey, S.K.S., Kokelj, V., Youngblut, D., 2007. Anomalous 20th century tree growth, Mackenzie Delta, northwest Territories, Canada. Geophys. Res. Lett. 34, L05714. http://dx.doi.org/10.1029/2006GL029139.

Ren, G., Chu, Z., Zhou, Y., Xu, M., Wang, Y., Tang, G., Zhai, P., Shao, X., Zhang, A., Chen, Z., Guo, J., Liu, H., Zhou, J., Zhao, Z., Zhang, L., Bai, H., Liu, X., Tang, H., 2005.
Recent progresses in studies of regional temperature changes in China. Clim. Environ. Res. 10, 701-716.

Salzer, M.W., Hughes, M.K., Bunn, A.G., Kipfmueller, K.F., 2009. Recent unprecedented tree-ring growth in bristlecone pine at the highest elevations and possible causes. Proc. Natl. Acad. Sci. 106, 20348-20353.

Shestakova, T.A., Gutiérrez, E., Kirdyanov, A.V., Camarero, J.J., Génova, M., Knorre, A.A., Linares, J.C., Resco de Dios, V., Sánchez-Salguero, R., Voltas, J., 2016. Forests synchronize their growth in contrasting Eurasian regions in response to climate warming. Proc. Natl. Acad. Sci. 113, 662-667.

Stokes, M.A., Smiley, T.L., 1996. An Introduction to Tree Ring Dating. The University of Arizona Press, Tucson, Arizona.

Su, J., Wang, X., 2017. Spatio-temporal variations in climate-growth relationships of three hardwood tree species across the north Zhangguangcai Mountains northeast China. Acta Ecol. Sinica 37, 1484-1495.

Sullivan, P.F., Mulvey, R.L., Brownlee, A.H., Barrett, T.M., Pattison, R.R., 2015. Warm summer nights and the growth decline of shore pine in Southeast Alaska. Environ. Res. Lett. 10, 124007.

Takahashi, K., Okuhara, I., 2012. Comparison of climatic effects on radial growth of evergreen broad-leaved trees at their northern distribution limit and co-dominating deciduous broad-leaved trees and evergreen conifers. Ecol. Res. 27, 125-132.

Tang, H., Zhai, P., Wang, Z., 2005. On change in mean maximum temperature, minimum temperature and diurnal range in China during 1951-2002. Clim. Environ. Res. 10, $728-735$.

Tardif, J., Stevenson, D., 2001. Radial growth-climate association of Thuja occidentalis L. at the northwestern limit of its distribution, Manitobas, Canada. Dendrochronologia 19, 179-187.

Thomas, P., Farjon, A., 2013. Pinus koraiensis. The IUCN Red List of Threatened Species 2013: e.T42373A2975987.

Vicenteserrano, S.M., Beguería, S., Lópezmoreno, J.I., 2010. A multiscalar drought index sensitive to global warming: the standardized precipitation evapotranspiration index. J. Clim. 23, 1696-1718.

Wang, X., Zhao, X., Gao, L., Jiang, Q., 2011. Age-dependent growth responses of Pinus koraiensis to climate in the north slope of Changbai Mountain, northeastern China. Acta Ecol. Sin. 31, 6378-6387.

Wang, X., Zhang, M., Ji, Y., Li, Z., Li, M., Zhang, Y., 2017. Temperature signals in tree-ring width and divergent growth of Korean pine response to recent climate warming in northeast Asia. Trees 31, 415-427.

Weber, P., Bugmann, H., Rigling, A., 2007. Radial growth responses to drought of Pinus sylvestris and Quercus pubescens in an inner-alpine dry valley. J. Veg. Sci. 18, 777-792.

Williams, A.P., Allen, C.D., Macalady, A.K., Griffin, D., Woodhouse, C.A., Meko, D.M., Swetnam, T.M., Rauscher, S.A., Seager, R., Grissino-Mayer, H.D., Dean, J.S., Cook, E.R., Gangodagamage, C., Cai, M., McDowell, N.G., 2013. Temperature as a potent driver of regional forest drought stress and tree mortality. Nat. Clim. Change 3 , 292-297.

Wimmer, R., Grabner, M., 1997. Effects of climate on vertical resin duct density and radial growth of Norway spruce (Picea abies (L.) Karst.). Trees 11, 271-276.

Wolkovich, E.M., Cook, B.I., Allen, J.M., Crimmins, T.M., Betancourt, J.L., Travers, S.E., Pau, S., Regetz, J., Davies, T.J., Kraft, N.J., Ault, T.R., Bolmgren, K., Mazer, S.J., McCabe, G.J., McGill, B.J., Parmesan, C., Salamin, N., Schwartz, M.D., Cleland, E.E., 2012. Warming experiments under predict plant phenological responses to climate change. Nature 485, 494-497.

Wu, F., Deng, H., 1996. Responses of broad-leaved Pinus koraiensis forests to global climate change. Acta Geogra. Sinica 51, 81-91.

Wu, Z., Raven, P.H., 1999. Flora of China, vol. 4 Missouri Botanical Garden Press and Science Press, St. Louis and Beijing TaxonID 200005340.

Wu, F., 2003. Assessment of eco-climatic suitability and climate change impacts on broadleaved Korean pine forest in Northeast China. Chin. J. Appl. Ecol. 14, 771-775.

Yao, Q., Wang, X., Xiao, X., 2015. Climate-growth relationships of Picea koraiensis and causes of its recent decline in Xiaoxing'an Mountains, China. Chin. J. Appl. Ecol. 26, 1935-1944.

Yu, D., Gu, H., Wang, J., Wang, Q., Dai, L., 2005. Relationships of climate change and tree ring of Betula ermanii tree line forest in Changbai Mountain. J. For. Res. 16, 187-192.

Yu, D., Liu, J., Lewis, B.J., Zhou, L., Zhou, W., Fang, X., Wei, Y., Jiang, S., Dai, L., 2013. Spatial variation and temporal instability in the climate-growth relationship of Korean pine in the Changbai Mountain region of Northeast China. For. Ecol. Manag. 300, 96-105.

Zhang, Y., Wilmking, M., 2010. Divergent growth responses and increasing temperature limitation of Qinghai spruce growth along an elevation gradient at the northeast Tibet Plateau. For. Ecol. Manag. 260, 1076-1082.

Zhao, C., Ren, G., Zhang, Y., Wang, Y., 2009. Climate change of the northeast China over the past 50 years. J. Arid Land Res. Environ. 23, 25-30.

Zhou, X., Zhang, Y., Sun, H., Chai, Y., Wang, Y., 2002. The effect of Climate change on population dynamics of Quercus mongolica in north Greater Xing'an Mountain. Acta Ecol. Sin. 22, 1035-1040.

Zhu, L., Yang, J., Zhu, C., Wang, X., 2015. Influences of gap disturbance and warming on radial growth of Pinus koraiensis and Abies nephrolepis in Xiaoxing'an Mountain, Northeast China. Chin. J. Ecol. 34, 2085-2095. 